\title{
Error Correction in the Intensive Reading Class of English Majors
}

\author{
Lei Zhu ${ }^{1}$ \\ ${ }^{1}$ School of Foreign Languages, University of Jinan, P.R. China \\ Correspondence: Lei Zhu, School of Foreign Languages, University of Jinan, Jinan, China. E-mail: \\ sfl_zhul@ujn.edu.cn
}

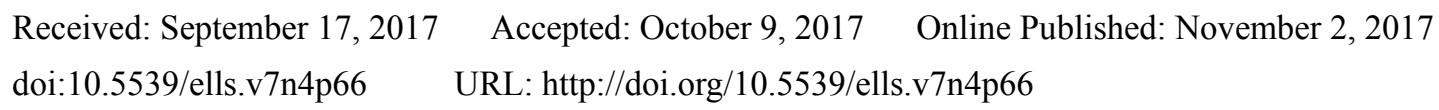

\begin{abstract}
This study explores similarities and differences of students' and teachers' attitudes toward corrective feedback in ESL teaching in terms of feedback efficacy and participant's perception of the feedback. Taking an empirical case study approach, the researcher followed closely six English teachers and two classes of English juniors. Questionnaires for both teachers and students and interviews with them respectively are the source of data. The research findings indicate that students are more confident about error correction than teachers. Subsequently, the direct corrective feedback seems to be more effective than indirect ones. And their attitudes about strategies seem to be a more decisive factor that influences the effectiveness of these strategies, because the strategy of negotiation of form, on which the students and the teachers hold the same attitude, enjoys the highest degree of students' perception.
\end{abstract}

Keywords: error correction, English teaching, corrective strategy

\section{Introduction}

Though the ultimate goal of foreign language teaching is to eliminate the errors, which is considered as a result of learners' incompetence (Brook, 1960, p. 58), its existence actually is of remarkable significance especially in revealing learners' cognitive process (Ellis, 2000). In the classes for English majors, an encouraging atmosphere seems to be more important than focusing on the correctness of their English. Errors are inevitable products of language learning. In the long run, a learner with correct but stumbled English may sooner or later get his or her language proficiency improved if provided with more opportunities communicating with native speakers; however, it is not the case with a stumbled but incorrect one, because by himself or herself, it is rather difficult to recognize the errors, let alone correct them. Therefore, feedback providers seem to be an important escort to error makers as long as they respond positively to the feedback the received. Feedback originally refers to the information that a receiver or a user gives back to its giver or maker. This concept was introduced to the field of education signifying the fact that students can obtain useful advice from teachers or classmates to ensure a worthy and thought provoking process.

\section{Literary Review}

The research into feedback remains an important issue in the field of Second Language Acquisition. After investigating a wide range of educational backgrounds, Black \& William (1998) suggested that feedback provide considerable benefit to language learners. The definition of feedback in the Oxford Advanced Learner's English-Chinese Dictionary (1989) is the "return of part of the output of a system to its source, esp. so as to modify the output". In ESL class, language input and output are considered two crucial parts in the learning process. The response sent to the output of the learners aims to help them to correct the errors and improve their language competence. Another definition was given by Ramaprasad (1983) as "information about the gap between the actual level and the reference level of a system parameter which is used to alter the gap in some way". This definition stresses the effect of feedback and reveals the idea that feedback must be transformed into action and revises the original practice. It is provided in various forms so long as it can motivate the students to "alter the gap" and turn out to be more competent intercultural communicators.

The lack of vocabulary and grammar and inadequate schema barriers the proficiency of language use for ESL students. Behaviorism holds that acquiring a new language is the same as forming a new linguistic habit which does not tolerate any mistakes. Those repeatedly occurring mistakes draw the attention of teachers and they tend to appeal to feedback to ajust their classroom teaching. It could be divided into direct and indirect feedback 
which is also referred to as explicit and implicit feedback. Direct response provides the students with the correct form or with explicit guidance to tell students how to correct their errors. It is thought to be better than indirect feedback especially for students of lower level (Ferris \& Roberts, 2001). Indirect feedback include "underlining the errors or using cursors to show omissions in the student's text or by placing a cross in the margin next to the line containing the error" (Ellis, 2009). Some scholars think it can guide the students to solve the problems by themselves and reflect their own language competence.

A series of researches conducted by Carroll \& Swain (1993) focus on the effectiveness of direct and indirect feedback. Their study shows that the participants which receive explicit information performing better than others. Similar conclusion could be found in the research of Nassaji \& Swain (2000, p. 49), claiming that "there was a more and explicit prompts to be more useful than less implicit prompts". However, there are still some negative opinions on explicit response arguing for the advantages of indirect feedback, because they believe that "explicit correction is usually ineffective in language behavior" (Lightbown, 2000, p. 446). Some scholars pointed out that explicit feedback may produce a negative influence on the communicative ability for the long-term study and cultivated the self-editing potential through implicit feedback (Woods, 1989; Hammerly, 1991; Myles, 2002).

In China, students mainly depend on English classes to improve their language proficiency. Thus, corrective feedback in class seems to be a vital element which is sure to have certain impact on their language learning. However, teachers and student's responses to error correction, the relation between their attitudes and the effectiveness, all these things still need attention. Therefore, this paper tends to find out the answers to the following three questions. 1) What are the respective attitudes of the teachers and the students towards error correction in class? 2) What are students' perceptions of teacher feedback?

\section{Research Methodology}

\subsection{The Design}

Considering the characteristics of research questions, a case study of six Chinese teachers and 63 students was conducted. Cohen, Manion \& Morrison (2000) stated that case studies seek to explore a phenomenon through careful investigation of one specific instance. They rely on different sources as questionnaires, interviews, observation, and documents, etc. The chief sources for this case study were questionnaires and interviews.

Questionnaires often take different names, such as "opinionnaires," "inventories," "surveys," and "indexes/indicators" (Aiken, 1997). It is considered as any written instruments that present respondents with a series of questions or statements to which they are to react either by writing out their answers or selecting from among existing answers"(Brown, 2001, p. 6). For question 1, 17 multiple-choice questions and 1 open-end question are involved in the questionnaires delivered to participants.

In interviews, the researcher conducts face-to-face interviews or interviews participants by telephone, or engages in group interviews with six or eight interviewees. The interviews consisted of a few unstructured and open-ended questions and are aimed to elicit opinions from the participants (Merriam, 1998; Bogdan \& Biklen, 1992; Creswell, 2002). In this research, all the teachers' interviews were conducted in a face-to-face way during the feedback coding process, while students' interviews took the form of group interview. For research question 2 , in-depth interviews were conducted to complement the results of the five-point Likert-scale questionnaires on students' perception of teacher feedback and both the response of the students and teachers when they fail to agree with each other on the feedback strategies.

\subsection{Subjects}

All the subjects of this research are 63 students and 6 teachers from English Department, School of Foreign Languages of University of Jinan.

The six teachers have the experience of teaching English majors for years, and they all have the academic background similar to most English teachers of universities located in second-line cities of China. They can represent the 117 staff members of Foreign Language School of University of Jinan. In terms of age, their condition can fully reveal the situation of the School. Table 1 demonstrates the age distribution. 
Table 1. Age distribution

\begin{tabular}{lll}
\hline Age & Participants & All teachers \\
\hline Below 30 & $1(16.6 \%)$ & $13(11.1 \%)$ \\
30-40 & $2(33.4 \%)$ & $44(37.6 \%)$ \\
40-50 & $2(33.4 \%)$ & $40(34.2 \%)$ \\
Above 50 & $1(16.6 \%)$ & $20(17.1 \%)$ \\
Total & $6(100 \%)$ & $117(100 \%)$ \\
\hline
\end{tabular}

Among the six teachers, there are 1 doctor, 4 master and 1 doctorate candidate. In terms of education background, they can also represent the whole School. The degree constitution is shown in Table 2.

Table 2. Degree distribution

\begin{tabular}{lll}
\hline Degree & Participants & All teachers \\
\hline Bachelor & $1(16.6 \%)$ & $22(18.8 \%)$ \\
Master & $3(50.2 \%)$ & $69(58.9 \%)$ \\
Doctorate candidate & $1(16.6 \%)$ & $9(7.7 \%)$ \\
Doctor & $1(16.6 \%)$ & $17(14.6 \%)$ \\
Total & $6(100 \%)$ & $117(100 \%)$ \\
\hline
\end{tabular}

In terms of gender, there are 74 female and 43 male English teachers in the School of Foreign languages. The percentage of female teachers is about $63.2 \%$, and is quite close to that of the female participants of this research with a proportion of $(66.6 \%)$.

Therefore, the six teachers chosen to take part in this research can typically represent the staff and could be a meaningful and reliable source.

The students chosen were English majors who got enrolled in the university in 2014. They take part in the courses lectured by the six teachers. They are not further divided into some groups or classes of a smaller size, because the research aims to reveal the response of students of different level towards on-class teacher feedback. All the students promised to participate in this program consistently.

\subsection{Data Collection}

A pilot study was conducted among fifteen students and three teachers before the real survey to ensure the validity and reliability of the questionnaires and the on-class activities. After they had finished the questionnaires and got familiar with the procedure of interview, the researcher discussed with them and made some revisions. Then the revised questionnaires were delivered to the 63 students randomly chosen from 4 classes and the 6 teachers. The 59 copies of the answered-questionnaires from the students were valid and all the 6 from the teachers were acceptable. Following the questionnaires, the six teachers' English classes were observed and the total time duration is 12 hours. Besides this, each teacher and all 63 students were interviewed after they were observed. Figure 1 illustrates the procedure of data collection.

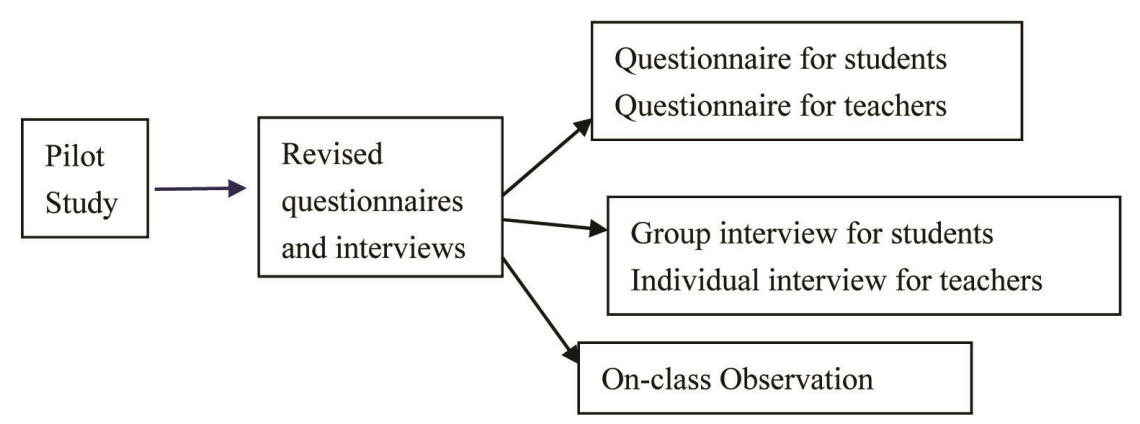

Figure 1. Procedure of data collection

The questionnaires were dispatched and collected to investigate participants' attitude and students' perception of teacher feedback. In-depth interviews following observation of English classes are aimed to further complement their opinions and perceptions. The interviews were recorded and transcripted. 


\subsection{Data Analysis and Findings}

\subsubsection{Teachers' and Students' Attitudes toward Error and Error Correction}

According to Hendrickson (1978), the following five questions were expounded very carefully. That is, is it necessary to correct the errors? When to correct them? What kind of errors should be corrected? How to correct them? Who corrects them?

In order to illustrate the attitudes of both the students and the teachers, for this part the questionnaires are based on the above questions. There are altogether 17 multiple choices and 1 open question. For the 17, the choices are made according to Likert Scale, that is, with five choices, as "strongly agree", "agree", "neutral", "disagree", and "strongly disagree". After data being analyzed by SPSS13.0, a descriptive account was given with mean, standard deviation, and so on.

For question 1 and 2, the same responses are received from both the teachers and the students. It shows that in general the teachers and most of the students do hold an active point of view toward the existence and the significance of errors. Question 3 and 4 are about whether students' errors should be corrected. Its necessity is confirmed by both sides. The only difference appears in their answers to question 5 (Frequent correction can undermine students' desire to answer questions on class.). For teachers, $M=4.61$, S.D. $=0.45$; while for students, $\mathrm{M}=2.6$, S.D. $=0.97$. It reveals that compared to teachers, students hold less worries about error correction on class.

Question 6 and 7 are designed to find out when to correct errors. The responses, with $M=3.17$ from teachers and $\mathrm{M}=2.89$ from students, show that both teachers and students prefer immediate correction on class although they admit that instant correction might block heir way of thinking sometimes, which they would like to sacrifice in order to horn their language muscles.

Question 8 to 11 are about what kind of errors should be corrected. Grammatical mistakes, improper use of expressions and wrong or inaccurate pronunciation are the main field which both teachers and students maintain the importance of correcting them. Of these three items, wrong or inaccurate pronunciation is the very first one that both sides confirm the necessity to correct. And grammatical mistakes rank the second and improper use of expressions the third.

Question 12 and 13 are made to investigate who is suitable to correct errors. It is found that in general both teachers and students would prefer teacher correcting errors when the students commit grammatical and phonetic mistakes. And $65 \%$ of the students and $75 \%$ teachers do think that self-correction is the best way to deal with improper use of expressions. Worth mentioning is the point that most students do not like peer correction.

Question 14 to 17 are about how to correct errors. Corrective feedback strategies, according to Lyster and Ranta (1997), can be grouped into six types, namely, explicit correction, recast, clarification request, metalinguistic feedback, elicitation, and repetition. The last four strategies are also named negotiation of form. Therefore, they are grouped into three types, that is, explicit correction, recast and negotiation of form. Among the participants, teachers $(M=2.79$, S.D. $=0.77)$ do not think explicit correction would be their choice on class, while students $(\mathrm{M}=4.05$, S.D. $=0.77)$ expect to be corrected explicitly on class. However, recast is teachers' favorite $(\mathrm{M}=3.7$, S.D. $=0.67)$, but not the students' $(\mathrm{M}=2.75$, S.D. $=1.21)$. The strategy of negotiation of form is both welcomed by the teachers $(\mathrm{M}=3.45)$ and the students $(\mathrm{M}=3.67)$.

\subsubsection{Teacher's Attitudes, Feedback Practices and the Results}

The data shows that teachers claim that the very first error type that they would like to correct on class is phonological mistakes, with grammatical errors and lexical ones following. However, what they really did on class is inconstant with it.

Table 3. Number and percentage of errors made by students and corrected by teachers

\begin{tabular}{llll}
\hline Type of error & Made by students & Corrected by teachers & Successful correction \\
\hline Grammatical & 45 & $19(33.3 \%)^{*}$ & $8(42.1 \%)$ \\
& $27.9 \%$ & $(11.8 \%)^{* *}$ & \\
\hline Phonological & 62 & $13(22.8 \%)$ & $10(76.9 \%)$ \\
& $38.5 \%$ & $(8.1 \%)$ & $16(64.0 \%)$ \\
\hline lexical & 54 & $25(43.9 \%)$ & $34(59.7 \%)$ \\
\hline Total & $33.6 \%$ & $(15.5 \%)$ & \\
& 161 & $57(100 \%)$ & $35.4 \%$ \\
\hline
\end{tabular}

Note. $*$ calculated out of 57 errors corrected by teachers; $* *$ calculated out of 161 errors made by students. 
Table 3 shows that the proportion of error types receiving corrective feedback is inconsistent with the rank that teachers claim what they would do on class. When being asked about the cause of the difference, the teachers admitted that lexical mistakes can be corrected proficiently without dragging behind the teaching plan while phonological correction requires students to follow the right pronunciation several times and grammatical correction is equally time-consuming since they need detailed explanation. Phonological errors are claimed to receive teachers' highest attention, but only $22.8 \%$ are corrected in practice. However, $64.0 \%$ of these corrected pronunciation are successful, which is the highest percentage of the three. The discrepancy between participants' expectation and the results may be caused by the fact that students are aware of the significance of English as a communicative tool to bridge different cultures. Therefore, they are stimulated to improve their proficiency especially speaking ability which definitely requires a low frequency of errors.

As for correction strategies, teachers prefer recast and negotiation of form to explicit correction, which is in accordance with their beliefs. (See Table4)

Table 4. Distribution of correction strategies

\begin{tabular}{llll}
\hline & Grammatical errors & Phonological errors & Lexical errors \\
\hline Explicit correction & 1 & 3 & 3 \\
$7(12.3 \%)$ & $(0.9 \%)$ & $(23.1 \%)$ & $(12.0 \%)$ \\
\hline Recast & 6 & 6 & 12 \\
$24(42.1 \%)$ & $(31.6 \%)$ & $(46.2 \%)$ & $(48.0 \%)$ \\
\hline Negotiation of form & 12 & 4 & 10 \\
$26(45.65 \%)$ & $(67.5 \%)$ & $(30.7 \%)$ & $(40.0 \%)$ \\
\hline Total & 19 & 13 & 25 \\
$57(100 \%)$ & $(100 \%)$ & $(100 \%)$ & $(100 \%)$ \\
\hline
\end{tabular}

\subsubsection{Correction Proficiency When Students and Teachers Hold Different Attitude}

As for correction strategies, students differ from teachers when confronting explicit correction and recast. Teachers tend to deny explicit correction due to their worries about hurting students' willingness to answer questions while students would like to receive direct correction instead of repeating their mistakes. They share the same opinion about negotiation of form. Table 3 reveals that recast as teachers' favorite seem to be the least effective way and explicit which is preferred by students enjoys the highest percentage of acceptance.

Table 5. Participants' attitude toward corrective feedback and the results

\begin{tabular}{|c|c|c|c|c|c|}
\hline \multirow[t]{2}{*}{ Corrective feedback } & \multicolumn{2}{|c|}{ Participants' attitude } & \multicolumn{3}{|l|}{ Results } \\
\hline & teachers & students & Accepted/corrected & Accepted/Delayed correction & Refused \\
\hline Explicit correction(7) & negative & affirmative & $5(71.4 \%)$ & $1(14.3 \%)$ & $1(14.3 \%)$ \\
\hline Recast (24) & affirmative & negative & $11(45.8 \%)$ & $5(20.8 \%)$ & $8(33.4 \%)$ \\
\hline Negotiation of form (26) & affirmative & affirmative & $18(69.2 \%)$ & $4(15.4 \%)$ & $4(15.4 \%)$ \\
\hline Total (57) & & & $34(59.7 \%)$ & $10(17.5 \%)$ & $13(22.8 \%)$ \\
\hline
\end{tabular}

\section{Discussion and Conclusion}

Students' different perceptions of teacher feedback and their performance on class reveal the discrepancy of their opinions on error correction.

Research question 1: What are the respective attitudes of the teachers and the students towards error correction in class?

According to the data collected and analyzed in 3.4.1, students tend to hold a more positive attitude than teachers who seem to worry about the malignant influence on students study confidence and willingness. Students tend to welcome immediate correction after they commit mistakes, because they do think it would be more effective than delayed correction. Teachers also share the same opinion since spoken feedback is not as endurable as written ones and instant correction is certainly impressive to mistake makers. More luckily, both teachers and students agree with each other on the necessity of correct grammatical, phonological and lexical errors, which surely ensures a harmonious atmosphere on class. However, discrepancies do appear concerning feedback strategies, with students preferring direct response whereas teachers are more likely to choose indirect way to correct various errors. 
Research question 2: What are students' perceptions of teacher feedback?

The different degrees of students' perception of teacher feedback are revealed in 3.4.4. The first reason to account for the low acceptance of recast among students is due to its inexplicitness. Teachers tend to use a roundabout way to correct errors, which makes it difficult to distinguish from noncorrective repetitions that share the same communicative function as recast. Moreover, in order to encourage voluntary answers on class, teachers would preface their conversation with those phrases and expressions to indicate a sort of support or praise, which might also narcotize students' awareness of a corrective feedback.

Explicit correction boasts of the highest percentage of acceptance among students firstly because of its explicitness of course. Teachers would directly point out the mistakes students commit. Far from being confused with noncorrective repetitions, explicit correction stays conspicuous with no misunderstanding and ambiguity. Another reason is that students like it and it is easy for them to accept it. When they are tired of recast on class, explicit correction seems to be fresh and eye-catching.

Negotiation of form is the very strategy that both teachers and students are fond of. Therefore, it becomes the most effective one among the three. This is achieved through constant communication that it requires between teacher and students on class when teacher guides them to realize errors and find out the correct form themselves, which activates students' schema and leads them to the right answer. This way, they would consider the relationship between form and communicative purpose before they speak out.

Based on this research, we come to the following conclusions. Students hold a more optimistic attitude toward errors and error correction on class. They maintain that though many mistakes they would commit in English practice it would not influence their confidence, that though many times they would be corrected it would not lessen their willingness to answer questions. However, teachers seem to be worried about this. The second finding is that teachers and students think differently about the corrective strategies especially explicit correction and recast. Students prefer to be corrected directly while teachers hope to do it in a roundabout way. In fact, this indirect corrective method as recast is resisted by most students. Finally, negotiation of form is the most efficient corrective strategy in practice, because both teachers and students stand on the same position towards this method. Next to it is explicit correction although teachers do not prefer it, students are really fond of this strategy. However, the one which students do not like while teachers tend to use frequently, that is recast, is pretty much refused by students. From this, we may say that students' attitude, rather than teachers', seems to be the crucial element that decides the efficiency of corrective strategies.

Thus, for error correction on class, the following conclusions could be drawn:

1) Both the students and teachers hold a positive view towards error correction. Students show enough trust to their teachers' feedback especially direct responses about grammar, vocabulary and pronunciation.

2) The feedback strategy on which teachers and students concur boasts to be the most effective method since its acceptance among students is above the others. However, as for those strategies on which students and teachers fail to agree with each other, students' attitude tend to be the decisive elements which is in accordance with the degree of their perceptions.

Because all the subjects coming from the same university and the number is very small, the results and conclusion may lack of generality and need further justification.

\section{References}

Aiken, L. R. (1997). Questionnaires and Inventories: Surveying Opinions and Assessing Personality. NY: Wiley.

Black, P., \& William, D. (1998). Assessment and classroom learning. Assessment in Education, 5(1), 7-74. https://doi.org/10.1080/0969595980050102

Bogdon, R., \& Biklen, S. K. (1998). Qualitative Research for Education: An Introduction to Theory and Methods (3rd ed.) Boston: Allyn and Bacon.

Brook, N. (1960). Language and Language Learning. New York: Harcourt, Brace \& World Inc.

Carroll, S., \& Swain, M. (1992). The role of feedback in adult second language acquisition: Error correction and $\begin{array}{lllll}\text { morphological } & \text { generalizations. } & \text { Applied } & \text { Linguistics, } & 13,\end{array}$ https://doi.Org/10.1017/S0142716400005555

Carroll, S., \& Swain, M. (1993). Explicit and implicit negative feedback: An empirical study of the learning of linguistic generalizations. Studies in Second Language Acquisition, 15, 337-386.

Cohen, L., Manion, L., \& Morrison, K. (2000). Research Methods in Education (5th ed.). London; New York: 
Routledge/Falmer. https://doi.org/10.4324/9780203224342

Creswell, J. W. (2002). Educational Research: Planning, Conducting, and Evaluating Quantitative and Qualitative Research. Upper Saddle River, NJ: Merrill/Pearson.

Doughty, C. (2001). Cognitive underpinning of focus on form. In P. Robinson (Ed.), Cognition and Second Language Instruction. Cambridge: Cambridge University Press. https://doi.org/10.1017/CBO9781139524780.010

Ellis, R. (1997) Second Language Acquisition. UK: Oxford University Press.

Ellis, R. (2009) A typology of written corrective feedback types. ELT Journal, 63(2), 97-107. https://doi.org/10.1093/elt/ccn023

Ferris, D. R., \& Roberts, B. (2001). Error feedback in L2 writing classes: How explicit does it need to be? Journal of second Language Writing, 10, 161-184. https://doi.org/10.1016/S1060-3743(01)00039-X

Hammerly, H. (1991). Fluency and Accuracy: Toward Balance in Language Teaching and Learning. Clevedon: Multilingual Matters LTD.

Lightbown, P. M. (2000). Anniversary article: Classroom SLA research and second language teaching. Applied Linguistics, 21(4), 431-462. https://doi.org/10.1093/applin/21.4.431

Loewen, S., \& Philip, J. (2006). Recasts in adult English L2 classroom: Characteristics, explicitness, and $\begin{array}{lllll}\text { effectiveness. The Modern } \quad \text { Language Journal, 90(4), } & \text { 536-556. }\end{array}$ https://doi.org/10.1111/j.1540-4781.2006.00465.x

Long, M. H. (1983). Native speaker/non-native speaker conversation and the negotiation of comprehensible input. Applied Linguistics, 4, 126-141. https://doi.org/10.1093/applin/4.2.126

Mangelsdorf, K. (1992). Peer reviews in the ESL composition classroom: What do the students think? ELT Journal, 46(3), 274-284. https://doi.org/10.1093/elt/46.3.274

Merriam, S. B. (1998). Qualitative Research and Case Study Applications in Education. San Francisco: Jossey-Bass.

Myles, J. (2002). Second language writing and research: The writing process and error analysis in student texts. TESL-EJ, 6(2), A-1.

Nassaji, H., \& Swain, M. (2000). A Vygotskian perspective on corrective feedback in L2: The effect on random versus negotiated help on the learning of English articles. Language Awareness, 9(1), 34-51. https://doi.org/10.1080/09658410008667135

Ramaprasad, A. (1983). On the definition of feedback. Behavioral Science, 28(1), 4-13. https://doi.org/10.1002/bs.3830280103

Rieber, L. J. (2006). Using peer review to improve student writing in Business courses. Journal of Education for Business, 7, 322-326. https://doi.org/10.3200/JOEB.81.6.322-326

Robb, T., Ross, S., \& Shortreed, I. (1986). Salience of feedback on error and its effect on EFL writing quality. TESOL Quarterly, 20(1), 82-94. https://doi.org/10.2307/3586390

\section{Copyrights}

Copyright for this article is retained by the author, with first publication rights granted to the journal.

This is an open-access article distributed under the terms and conditions of the Creative Commons Attribution license (http://creativecommons.org/licenses/by/4.0/). 